\title{
Optimization Effect of Superdisintegrants and Subliming Agent on Orodispersible Tablet of Loratidine
}

\author{
Shivani Mehta*1, Dr. Shridhar Pandya ${ }^{2}$ \\ Sheridan college of applied science \\ *Corresponding Author: Shivani Mehta, Sheridan college of applied science, India.
}

\begin{abstract}
Loratidine is an anti-histamine drug. Bitter taste of the Loratidine is a problem in ensuring patient compliance. Resinates of Loratidine were prepared with Indion 234 and loading process was optimized. A $3^{2}$ factorial design was used for formulation development of orodispersible tablet of these taste masked resinates. The amount of subliming agent (camphor) and superdisintegrants (sodium starch glycolate) were taken as formulation variables (factors) for optimizing disintegration time, drug release after 15 minutes and friability as dependent or response variables. A mathematical model was generated for each response parameter. The disintegration time was found to linearly increase with the increase in the amount of superdisintegrants. The percentage friability showed no definite relationship with either amount of subliming agent or superdisintegrants. The optimum formulations were chosen by grid search method and their predicted results were found to be in close agreement with experimental findings.
\end{abstract}

Keywords : oral disintegrating tablets, Loratidine, factorial design, contour plots, response surface methodology

\section{INTRODUCTION}

Fast disintegrating /dissolving drug delivery system is a novel system which has advantages such as administration without water anytime and anywhere specially for geriatric and pediatric patients. Various superdisintegrants like crosscarmellose sodium, sodium starch glycolate and crosspovidone are used. However; various other techniques are reported such as lyophillization ${ }^{6}$ and vacuum drying ${ }^{7,8}$ these involve maximization of the pore structure of tablet matrix, thus leading to enhanced disintegration. But it yields tablets, which are fragile and hygroscopic. Sublimation, a useful technique that gives less fragile tablets by formation of a porous hydrophilic matrix which picks up disintegrating medium and disintegrates quickly ${ }^{7}$ Various other patented technologies like Zydis, Oraquick, Durasolv, Flash dose; Wowtab etc are also been used to prepare fast disintegrating tablets. ${ }^{8}$ The main aim of the current study was to develop and optimize the fast disintegrating tablets of taste-masked ondansetron resinates prepared by wet granulation. $3^{2}$ factorial design was employed to investigate the effect of two independent variable (factors) i.e.; amount of subliming agent:: and amount of superdisintegrants. ${ }^{9,10}$ The disintegration time, release after 15 minutes and percentage friability were taken as the response variables.

\section{MATERIALS AND METHODS}

\section{Method of Analysis ${ }^{4}$}

The drug was estimated spectrophotometrically at $240 \mathrm{~nm}$ using JASCO-V520 UV VIS spectrophotometer over concentration range of $2-12 \mu \mathrm{g} / \mathrm{ml}$.

\section{Drug Loading}

For drug loading batch method ${ }^{1}$ was used.

\section{Taste Evaluation}

Two methods are used for taste evaluation including Determination of threshold bitterness concentration \& In-vitro evaluation of bitter taste of Resinates. ${ }^{5,6}$ 
Optimization Effect of Superdisintegrants and Subliming Agent on Orodispersible Tablet of Loratidine RESULT \& DisCUSSION

Formulation Development of Orodispersible Tablets

Table1. Selection of Resin

\begin{tabular}{|c|c|c|c|}
\hline \multirow{2}{*}{ RESIN } & \multicolumn{2}{|c|}{ CONCENTRATION } & PERCENTAGE DRUG BOUND TO \\
\cline { 2 - 3 } & \multicolumn{2}{|c|}{ Drug Resin } & $87.66 \pm 0.12$ \\
\hline Indion 204 & 100 & 100 & $93.31 \pm 0.22$ \\
Indion 234 & 100 & 100 & $46.19 \pm 1.05$ \\
\hline Indion 264 & 100 & 100 & \\
\hline
\end{tabular}

Indion-234 give best loading efficiency and also threshold bitterness concentration and most of amount to drug present in resinate is more in the volunteers selected $20 \mathrm{mcg} / \mathrm{ml}$ threshold loratidine- Indion: 234 resinate. Taste evaluation bitterness concentrations in $2 \mathrm{~min}$. hence is done by in vitro taste determination of satisfactorily taste masked occur.

Table 2. Evaluation test for nine optimized formulation

\begin{tabular}{|c|c|c|c|}
\hline \% friability & $\begin{array}{c}\text { Disintegration } \\
\text { time(secs) } \pm \text { SD }\end{array}$ & \% assay & Wetting time. \\
\hline $0.595 \pm 0.044$ & $160 \pm 2.588$ & 98.64 & $142 \pm 1.14$ \\
$0.630 \pm 0.046$ & $105 \pm 2.236$ & 99.21 & $81 \pm 1.673$ \\
$0.583 \pm 0.058$ & $67 \pm 3.536$ & 99.42 & $52 \pm 2.00$ \\
$0.822 \pm 0.029$ & $55 \pm 2.303$ & 98.41 & $43 \pm 1.483$ \\
$0.782 \pm 0.031$ & $34 \pm 1.673$ & 98.53 & $25 \pm 1.581$ \\
$0.813 \pm 0.023$ & $28 \pm 2.881$ & 98.02 & $19 \pm 1.541$ \\
$1.048 \pm 0.019$ & $40 \pm 2.775$ & 97.93 & $28 \pm 2.236$ \\
$0.957 \pm 0.047$ & $32 \pm 2.387$ & 99.78 & $21 \pm 3.050$ \\
$1.035 \pm 0.086$ & $15 \pm 3.209$ & 97.23 & $9 \pm 1.673$ \\
$0.595-1.048$ & $15-160$ & $97.23-99.78$ & $9 \pm 142$ \\
\hline
\end{tabular}

Table 3. Six intensive search formulation

\begin{tabular}{|c|c|c|c|c|c|c|}
\hline \multirow{2}{*}{ Code } & \multicolumn{2}{|c|}{ Formulation composition (mg) } & $\begin{array}{c}\text { Weight (mg) } \\
\text { Mean } \pm \text { S.D. }\end{array}$ & $\begin{array}{c}\text { Hardness (kg) } \\
\text { Mean } \pm \text { S.D. }\end{array}$ & $\begin{array}{c}\text { Diameter (mm) } \\
\text { Mean } \pm \text { S.D. }\end{array}$ & $\%$ Assay \\
\cline { 2 - 3 } & Camphor & SSG & & & & \\
\hline OS1 & 29.75 & 19.4 & $200.13 \pm 1.35$ & $3.1 \pm 0.27$ & $8 \pm 0.02$ & 98.45 \\
\hline OS2 & 26.50 & 21.4 & $201.09 \pm 1.24$ & $3.5 \pm 0.62$ & $8 \pm 0.01$ & 99.71 \\
\hline OS3 & 30 & 24 & $200.32 \pm 1.52$ & $3.2 \pm 0.71$ & $8 \pm 0.04$ & 98.18 \\
\hline OS4 & 26 & 21.2 & $200.45 \pm 1.16$ & $3.4 \pm 0.35$ & $8 \pm 0.02$ & 98.57 \\
\hline OS5 & 22 & 23.8 & $200.17 \pm 1.28$ & $3.7 \pm 0.59$ & $8 \pm 0.03$ & 97.94 \\
\hline OS6 & 24 & 19.20 & $200.27 \pm 1.61$ & $3.6 \pm 0.52$ & $8 \pm 0.05$ & 98.82 \\
\hline \multicolumn{3}{|c|}{ Broad range } & $200.13-01.09$ & $3.1-3.7$ & $8-8$ & 99.71 \\
\hline
\end{tabular}

\section{DRUG RELEASE}

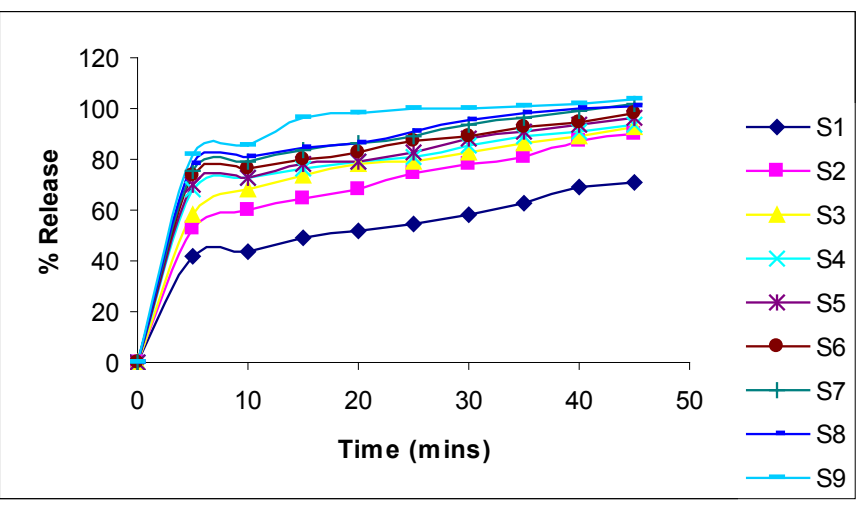

Figure 1. Drug Release Profile in Nine Optimized Formulation 
Optimization Effect of Superdisintegrants and Subliming Agent on Orodispersible Tablet of Loratidine
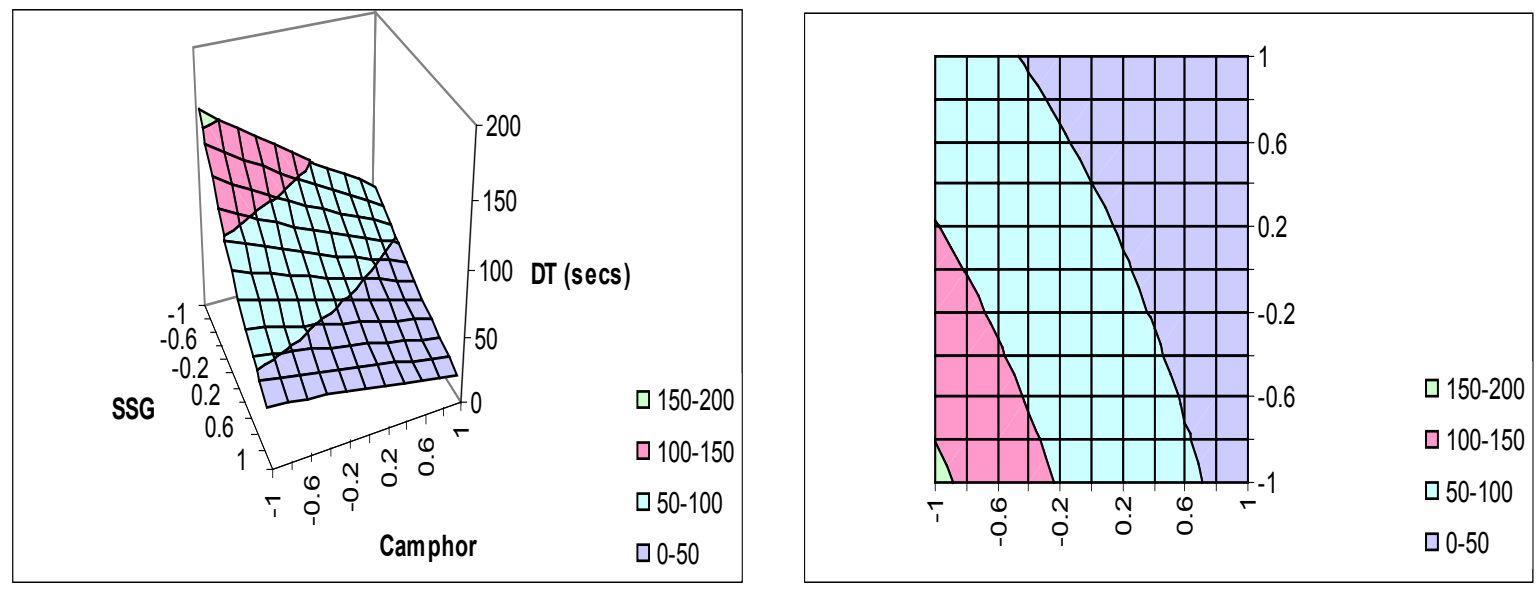

Response surface plot and contour plot of DT
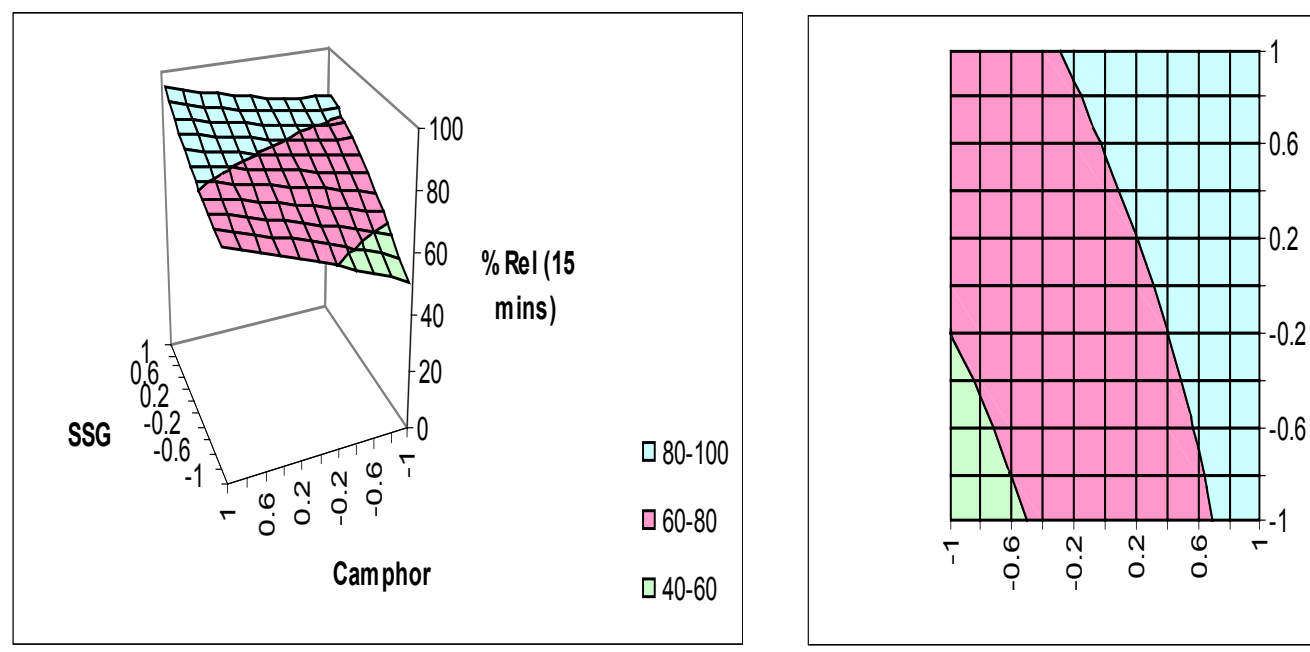

$\square 80-100$

$\square 60-80$

$\square 40-60$

Response surface plot and contour plot of \% Release in 15 mins.
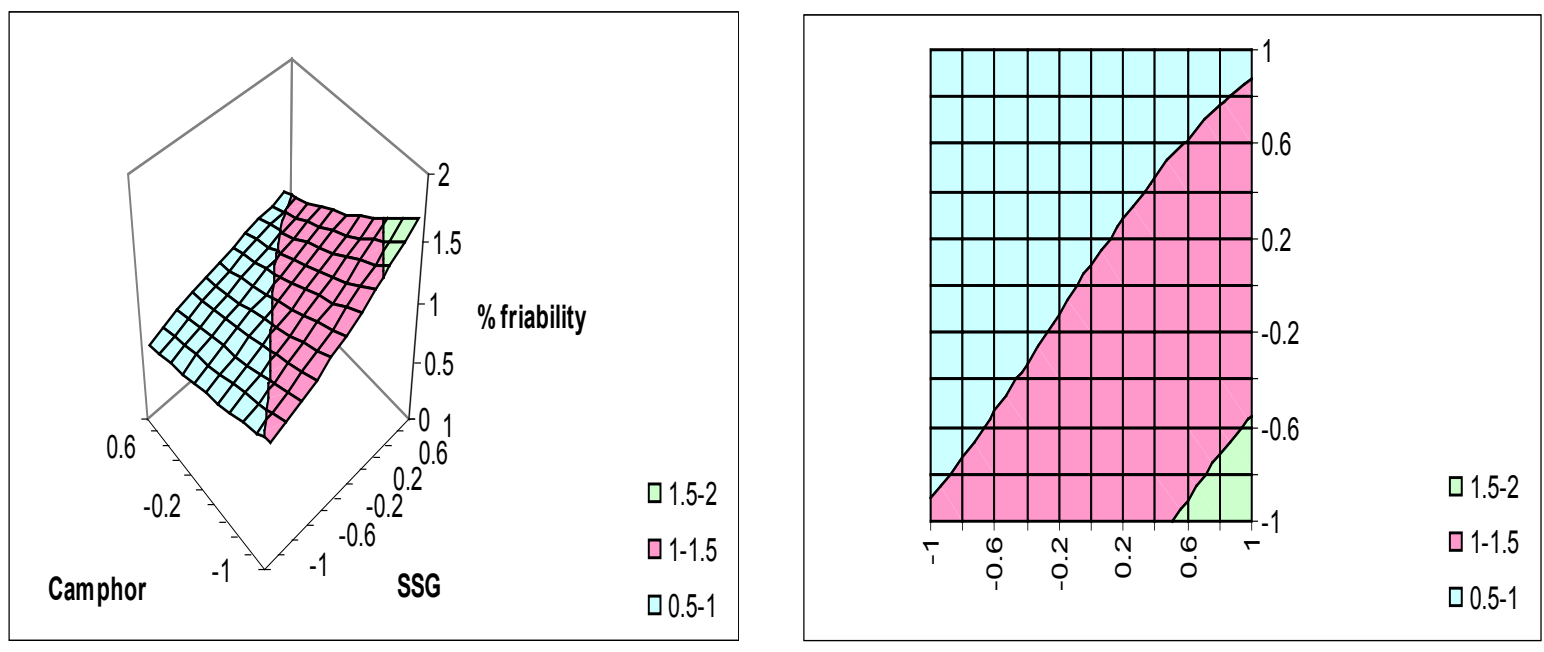

Response surface plot and contour plot of DT

Figure 2. Response surface \& contour plot

Response surface is 3D dimensional plot, response variable verses two independent and contour plot is $2 \mathrm{D}$ dimensional plot of variable. 
Optimization Effect of Superdisintegrants and Subliming Agent on Orodispersible Tablet of Loratidine COMPARISON OF OPTIMUM FORMULATION sublimation and effervescent technique. Viz OS4 and WITH CONVENTIONAL TABLETS OF OE1. LORATIDINE

Based on the least disintegration time and faster drug, one optimum formulation each was selected from
These formulations were compared with the conventional marketed tablets of Loratidine having an equivalent dose of $30 \mathrm{mg}$.

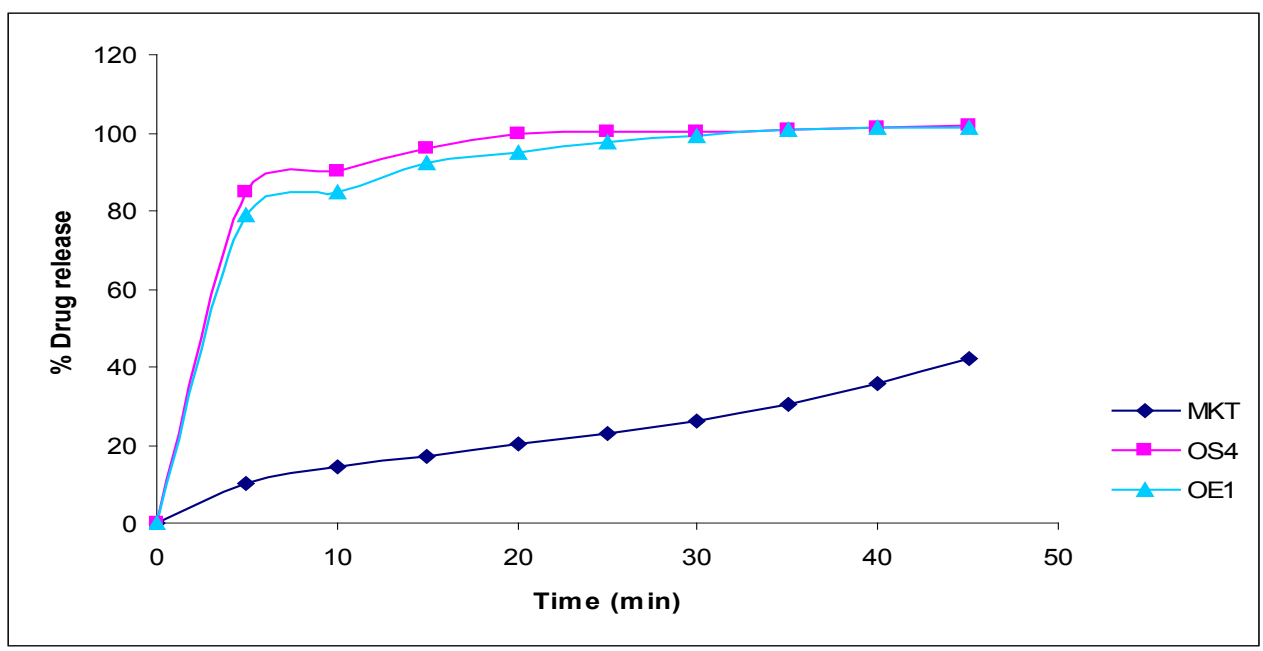

Figure 3. Comparison of sublimation and effervescent method with marketed product

Above graphical illustration represents both methods (OS \& OE) that gives better release as compare to marketed products.

\section{CONCLUSION}

Indion-234 give bestloading efficiency and also amount to drug present in resinate is more in loratidineIndion: 234 resinate. Taste evaluation is done by in vitro taste determination of threshold bitterness concentration and most of the volunteers selected $20 \mathrm{mcg} / \mathrm{ml}$ threshold bitterness concentrations in 2 min. hence satisfactorily taste masked occur. The reason behind this was because of significantly faster disintegration of Orodispersible tablets i.e. OE4 and OE1 as compared to the marketed formulation the release of the drug was faster. In Orodispersible tablets, the disintegration process starts in the oral cavity itself, thereby accelerating the dissolution process in the GIT which further bring about faster absorption of the drug. Both methods (OS \& OE) that gives better release as compare to marketed products. The stability studies of the Orodispersible tablets revealed that no significant changes in the physical parameters when stored at temperature and humidity conditions of $40 \pm 2^{\circ} \mathrm{C} / 75 \pm 5 \% \mathrm{RH}$ and at room temperature. No significant reduction in the content of the active drug was observed over a period of two months hence shelf life of the formulation could extrapolate to a minimum of two years.

\section{ACKNOWLEDGEMENT}

Authors are grateful to:

$\checkmark \quad$ Vaikunth bulk Chemical Pharmaceutical Ltd. Panoli: Ankleshwar for providing loratidine as a gift sample.

$\checkmark \quad$ Ion exchange India ltd. Mumbai for providing Indion 204, 234 and 264.

$\checkmark$ Biogen Pharmaceutical: Sayan, providing manufacturing and evaluation facility.

\section{REFERENCES}

[1] Vimla.D et al., In Advances in controlled and Novel Drug Delivery, 1st Edn., N. K. Jain, 2001; 290-306.

[2] Reddy L.H., Ghosh B, Fast Dissolving Drug Delivery systems, A Review of the literature, Indian J Pharm Sci., 2002; 64: 331-336.

[3] Biradar SS, Bhagavati ST, Kuppasad IJ. Fast Dissolving Drug Delivery Systems, A Brief Overview, The Int J. Pharmacology, 2006Vol. 4: 27-33.

[4] SohiH., SultanaY, Khar RK. Taste masking technologies in oral pharmaceuticals: Recent development and approaches, Drug Dev. Ind. Pharm, 2004; 30:429-448. 
Optimization Effect of Superdisintegrants and Subliming Agent on Orodispersible Tablet of Loratidine

[5] Determination of bitterness value In Quality control methods for medicinal plant materials. http: //www.who.int.

[6] Kuchekar BS., Badhan AC., Mahajan HS, Mouth dissolving tablets: A Novel Drug Delivery System, Pharm Times, 2003; 35:7-9.

[7] Corveleyn S., Remon JP, Formulation and Production of Rapidly disintegrating tablets, $2001 ; 49-58$
[8] Hughes L. Ion Exchange Resinates-the Technology behind the Mystery, Pharmaceutical Technology; 17; 2005:38-42.

[9] State-Ease, Design -Expert Software, Version 7, USA.

[10] Kwala A., Vincent H., Lee L, Geaham D. Mathew K, Fast disintegrating tablets, , US Patent 6733781, December 6,2000.

Citation: Shivani Mehta, Dr. Shridhar Pandya. Optimization Effect of Superdisintegrants and Subliming Agent on Orodispersible Tablet of Loratidine. Archives of Diabetes and Endocrine System. 2020; 3(1): 01-05.

Copyright: (C) 2020 Shivani Mehta, Dr. Shridhar Pandya. This is an open access article distributed under the Creative Commons Attribution License, which permits unrestricted use, distribution, and reproduction in any medium, provided the original work is properly cited. 